\title{
Effect of Compressive Loading on Chondrocyte Differentiation in Agarose Cultures of Chick Limb-Bud Cells
}

\author{
S. H. Elder, *J. H. Kimura, L. J. Soslowsky, M. Lavagnino, and S. A. Goldstein \\ Orthopaedic Research Laboratories, University of Michigan, Ann Arbor, \\ and *Bone and Joint Center, Henry Ford Hospital, Detroit, Michigan, U.S.A.
}

\begin{abstract}
Summary: It is well established that mechanical loading is important to homeostasis of cartilage tissue, and growing evidence suggests that it influences cartilage differentiation as well. Whereas the effect of mechanical forces on chondrocyte biosynthesis and gene expression has been vigorously investigated, the effect of the mechanical environment on chondrocyte differentiation has received little attention. The long-term objective of this research is to investigate the regulatory role of mechanical loading in cell differentiation. The goal of this study was to determine if mechanical compression could modulate chondrocyte differentiation in vitro. Stage 23/24 chick limb-bud cells, embedded in agarose gel, were subjected to either static (constant $4.5-$ $\mathrm{kPa}$ stress) or cyclic $(9.0-\mathrm{kPa}$ peak stress at $0.33 \mathrm{~Hz}$ ) loading in unconfined compression during the initial phase of commitment to a phenotypic lineage. Compared with nonloaded controls, cyclic compressive loading roughly doubled the number of cartilage nodules and the amount of sulfate incorporation on day 8 , whereas static compression had litle effect on these two measures. Neither compression protocol significantly affected overall cell viability or the proliferation of cells within nodules. Since limb-bud mesenchymal cells were seeded directly into agarose, an assessment of cartilage nodules in the agarose reflects the proportion of the original cells that had given rise to chondrocytes. Thus, the results indicate that about twice as many mesenchymal cells were induced to enter the chondrogenic pathway by cyclic mechanical compression. The coincidence of the increase in sulfate incorporation and nodule density indicates that the primary effect of mechanical compression on mesenchymal cells was on cellular differentiation and not on their subsequent metabolism. Further studies are needed to identify the primary chondrogenic signal associated with cyclic compressive loading and to determine the mechanism by which it influences commitment to or progression through the chondrogenic lineage, or both.
\end{abstract}

Many in vitro studies have demonstrated that chondrocyte biosynthetic activity, in suspension cell cultures $(6,19)$ and cartilage explants $(25,26,29,34)$, is strongly influenced by mechanical loading. In addition, there is considerable indirect evidence that the mechanical environment plays a role in chondrocyte differentiation during embryonic development and tissue regeneration. For example, a continuously applied, constant compressive force has been shown to stimulate type-II collagen and aggrecan expression in collagen gel cultures of embryonic mouse limb-bud cells (31). Also, intermittent articulation of embryonic chick membrane bones resulted in the formation of secondary cartilage in organ culture whereas the maintenance of a constant pressure or no mechanical stimulation produced none (12). In ovo paralysis of

Received October 27, 1998; accepted July 19, 1999.

Address correspondence and reprint requests to S. A. Goldstein at Orthopaedic Rescarch Laboratories, University of Michigan, Room G161, 400 N. Ingalls, Ann Arbor, MI 48109-0486; U.S.A. E-mail: stevegld@umich.edu chicks also inhibited the formation of secondary cartilage on membrane bones (22). Furthermore, secondary cartilage differentiation in midpalatal rat sutures was down-regulated by a static tensile force applied in vivo (30). Finally, finite element computer models successfully predicted the pattern of cartilage formation in human prenatal and postnatal femoral anlage on the basis of a theory that a history of intermittent hydrostatic compression promotes chondrocyte differentiation (9).

There have also been observations of the influence of mechanical loading on tissue differentiation during wound healing. For instance, clinicians have observed localization of the cartilaginous callus to the concave, compressed side of angulated fractures (28). In addition, less-stable fixation of rabbit tibial fractures resulted in a higher proportion of cartilage within the healing tissue relative to fractures that were rigidly fixed (2), and cartilage differentiation in periosteal grafts used to repair articular cartilage defects in rabbits was enhanced by continuous passive motion 


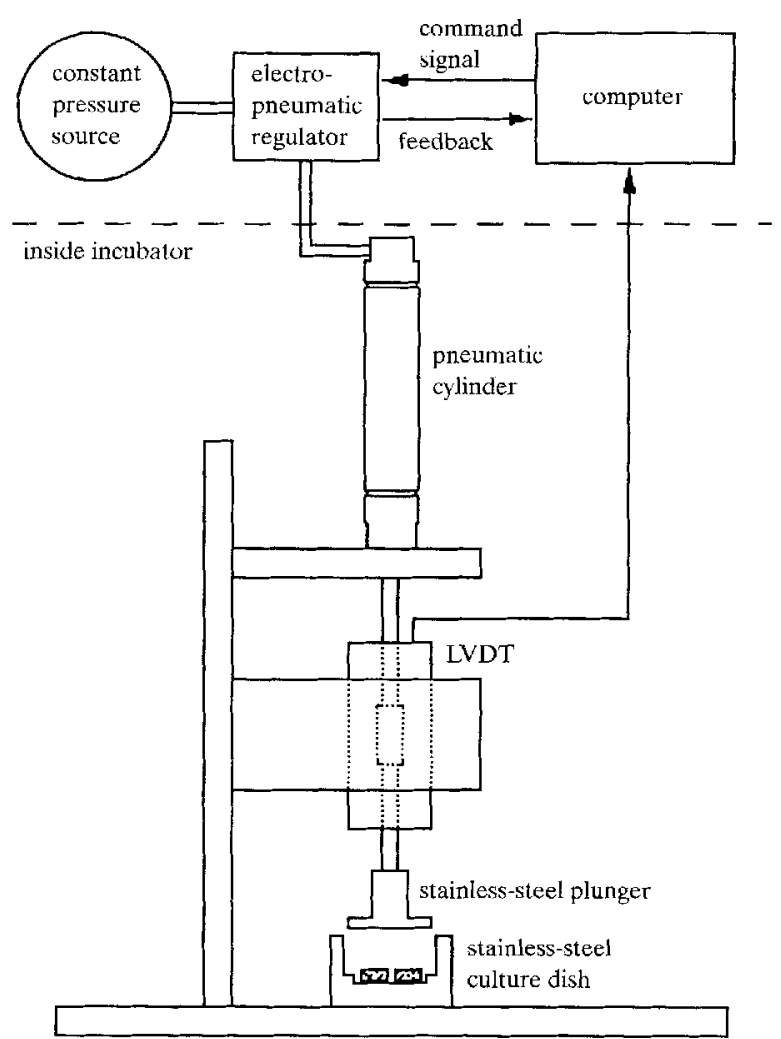

FIG. 1. Schematic diagram of the electropneumatic loading apparatus. The computer is used to generate a voltage command signal by LabView software (National Instruments, Austin, TX, U.S.A.). The electropneumatic regulator converts this signal into a pressure wave that drives the pneumatic cylinder (coupled to the plunger). The linear variable differential transformer (LVDT) measurcs displacement of the plunger.

compared with immobilization (23).

With the notable exception of Takahashi et al. (31), these studies generally seem to indicate that some form of intermittent mechanical compression enhances cartilage differentiation. On the basis of these findings, we hypothesized that short-term cyclic compressive loading of undifferentiated mesenchymal cells would stimulate chondrocyte differentiation but that static compression would not. Thus, we predicted a response to short-term compressive loading similar to that displayed by mature chondrocytes with respect to matrix biosynthesis.

The purpose of this study was to compare the effects of nonloaded, uniaxial cyclic compression and uniaxial static compression on chondrocyte differentiation in agarose gel cultures of chick limb-bud cells.

\section{MATERIALS AND METHODS}

\section{Cell Isolation and Culture}

Wing and leg-limb buds from Hamburger-Hamilton stage 23/24 (13) White Leghorn chick embryos (incubated 4.5 days) were removed in Tyrode's solution $\left(4^{\circ} \mathrm{C}\right)$ and transferred to Moscona's soIution (calcium and magnesium-free Tyrode's solution) $\left(4^{\circ} \mathrm{C}\right)$ for 10 minutes to loosen the ectoderm. The buds were enzymatically digested for 45 minutes at $37^{\circ} \mathrm{C}$ in a solution containing $0.25 \%$ trypsin-EDTA (Sigma, St. Louis, MO, U.S.A.) and $0.1 \%$ collage- nase (CLS-2: Worthington, Freehold, NJ, U.S.A.). An equal volume of bovine calf serum (HyClone Laboratories, Logan, UT, U.S.A.) was then added to deactivate the enzymes. Cells were gently pipetted and passed through a syringe filter with a pore size of $25 \mu \mathrm{m}$. They were pelleted by centrifugation at $200 \times \mathrm{g}$ and resuspended in a Dulbecco's modified Eagle medium/F12 culture medium (1:1) (GiBco BRL, Gaithersburg, MD, U.S.A.) containing 50 $\mu \mathrm{g} / \mathrm{ml}$ gentamicin (GiBco BRL). The cells were counted on a hemocytometer, centrifuged, and resuspended at a concentration of $6.0 \times 10^{6}$ cells $/ \mathrm{ml}$ in medium supplemented with $2 \%$ fetal calf scrum (HyClone Laboratories). The isolation process did not completely disperse the cells, and the resulting suspension contained aggregates (or clusters) and singlc cells. Individual cells within aggrcgates were counted whenever they could be discerned. This process of limited disaggregation was adopted because further cell dispersion by longer digestion and vigorous pipetting scverely reduced chondrocyte differentiation.

The cell suspension $\left(37^{\circ} \mathrm{C}\right)$ was mixed with an equal part of $6.0 \%$ low-melting-temperature agarose (ScaPlaque; FMC Bioproducts, Rockland, ME, U.S.A.) at $55^{\circ} \mathrm{C}$, poured between parallel glass plates separated by 2 -mm-thick spacers, and refrigerated for 10 minutes to allow the agarose to gel. The final agarose and cell concentrations were $3.0 \%$ and $3.0 \times 10^{6} \mathrm{cells} / \mathrm{ml}$, respectively. Cylindrical disks, $11 \mathrm{~mm}$ in diameter $\times 2 \mathrm{~mm}$ thick, were cut from the gel slab. These gel disks were placed in custom stainless-stecl culture dishes and covered with Dulbecco's modified Eagle me$\operatorname{dium} / \mathrm{F} 12$ culture medium (1:1) containing $50 \mu \mathrm{g} / \mathrm{ml}$ gentamicin and $2 \%$ fetal calf serum (14). The culture medium was not sup-

$\mathbf{A}$

Time (minutes)
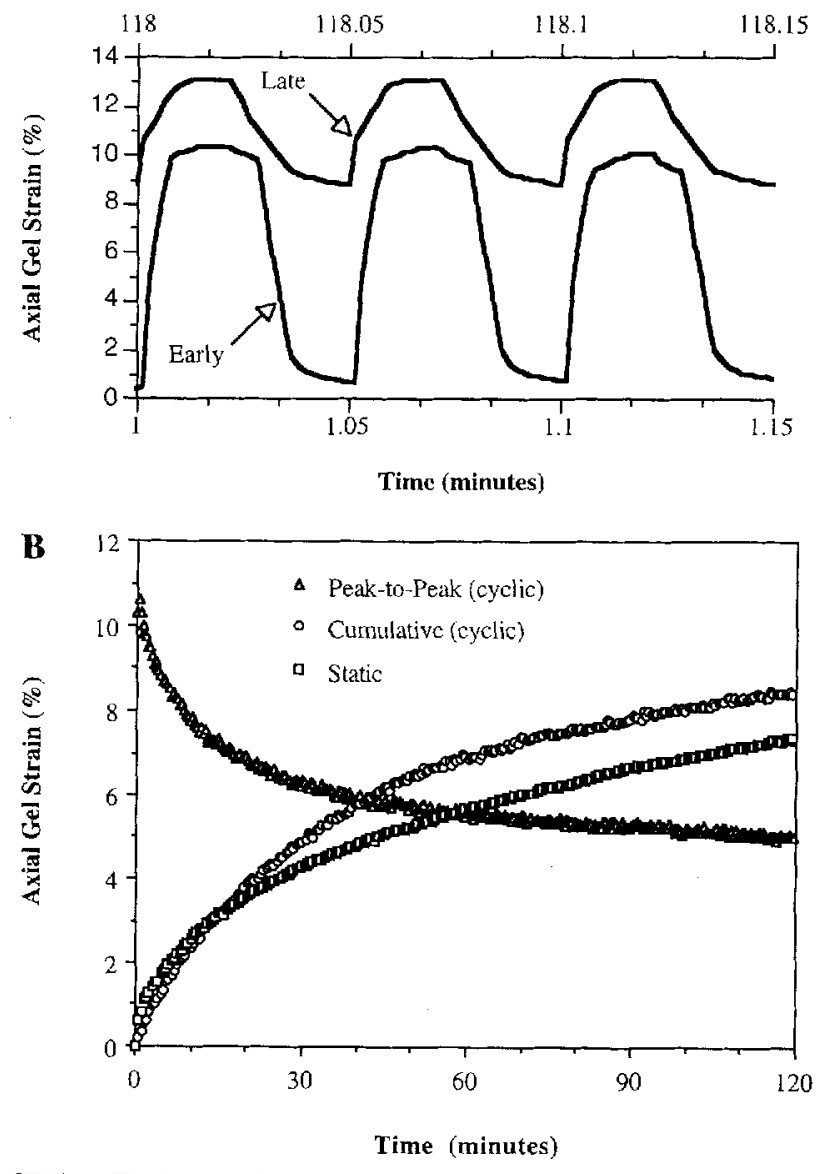

FIG. 2. Typical strain patterns for static and cyclic loading. Snapshots of total strain after 1 minute (early) and 118 minutes (late) of loading (A). Complete cumulative and static strain histories for a single loading session (B). 
A

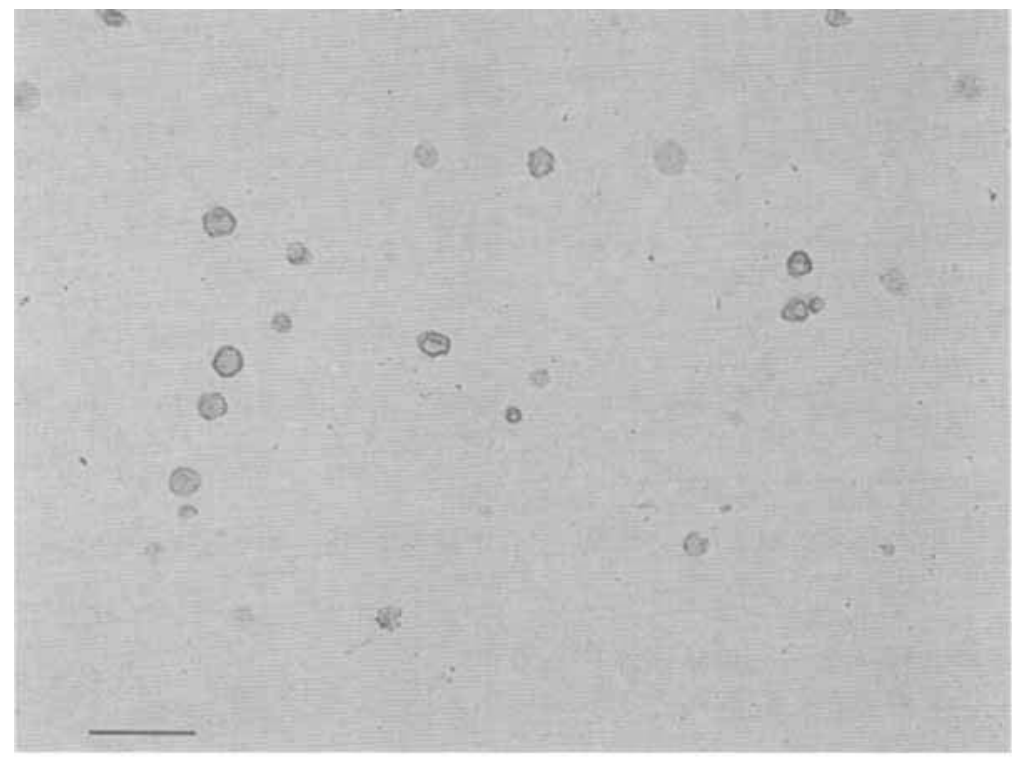

$\mathbf{B}$

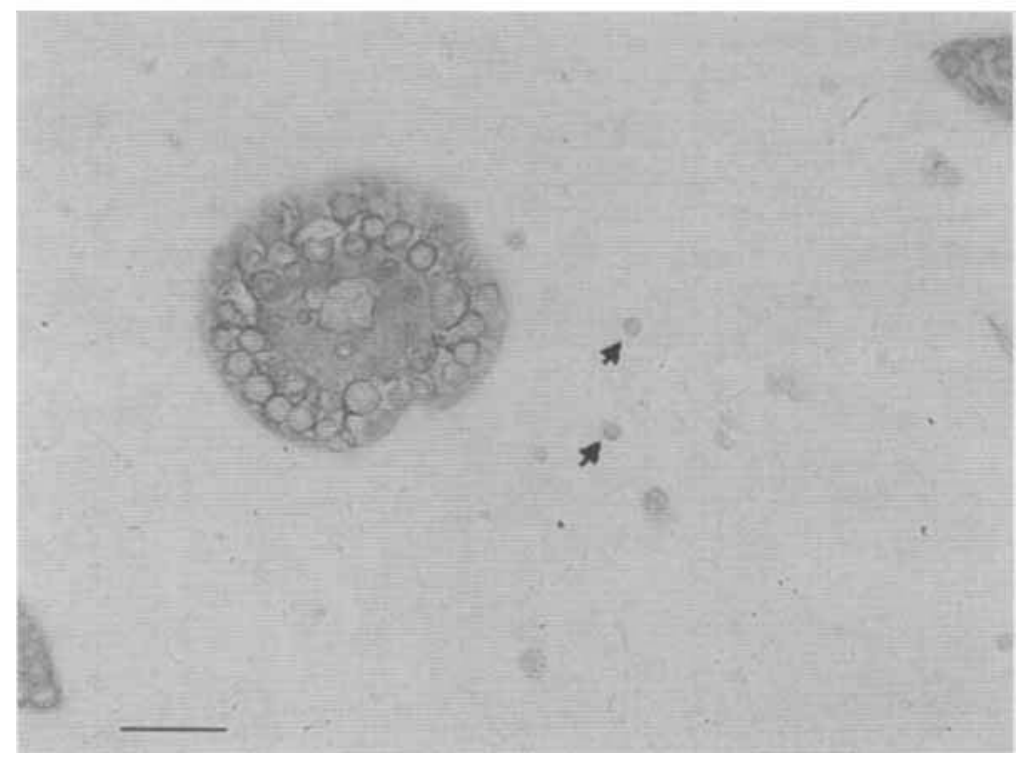

FIG. 3. Hislologic sections $(7 \mu \mathrm{m})$ from control cultures stained with hematoxylin and toluidine blue. Days 0 (A) and 8 (B). Arrows indicate nonchondrocytic cells in the culture at day 8 . Bars $=50 \mu \mathrm{m}$.

plemented with ascorbate. The disks were maintained at $37^{\circ} \mathrm{C}$ in a humidified atmosphere of $95 \%$ air: $5 \% \mathrm{CO}_{2}$.

\section{Compression}

Each experimental group was cultured in a separate dish containing seven cell-agarose disks. The experiment was repeated once (except for sham loading), with cells from a separale batch of chick embryos. Results from the two experiments were pooled for statistical analyses. A custom-designed elcctropneumatic apparatus (Fig. 1) was used to apply static $(n=14)$ and cyclic $(\mathrm{n}=$ 14) loads in unconfined compression. The cyclic loading waveform was a $0.25-9.0-\mathrm{kPa}$ sinusoid with a frequency of $0.33 \mathrm{~Hz}$ and a duration of 2 hours. Static loading was a constant $4.5-\mathrm{kPa}$ stress applied for 2 hours. During static and cyclic compressive loading, the maximum displacement was limited to $0.4 \mathrm{~mm}(20 \%$ axial strain) by a $1.6-\mathrm{mm}$ stainless-steel spacer. Sham-loaded controls $(\mathrm{n}=7)$ were placed in the device, and the plunger was fixed in position such that it barely made contact with the disks. No additional displacements were applied. Nonloaded controls $(n=14)$ were never placed in the loading device.

Each experimental disk was subjected to three loading sessions of 2 hours duration, the first beginning within 24 hours of cell isolation. Subsequent loading sessions were 24 and 48 hours later. Following the third day of loading, a period of 5 days during which no load was applied was allowed for chondrocyte differentiation.

\section{Histology}

On day 8 in culture ( 5 days since the last loading session), each agarose disk was cut in 1wo; half was used for histological analysis and the other half for determination of the glycosaminoglycan synthesis rate. Specimens to be analyzed by light microscopy werc fixed for 24 hours in a solution of $0.7 \%$ (wt/vol) ruthenium hexammine trichloride, $2 \%(\mathrm{vol} / \mathrm{vol})$ glutaraldehyde, and $0.05 \mathrm{M}$ sodium cacodylate $(15)$ at $4^{\circ} \mathrm{C}$. They were postfixed for 24 hours in the same solution without ruthenium hexammine trichloride, washed several times in a buffer of $0.1 \mathrm{M}$ sodium cacodylate and $0.065 \mathrm{M}$ $\mathrm{NaCl}$, rinsed briefly in distilled water, and stored at $4^{\circ} \mathrm{C}$ in $70 \%$ 


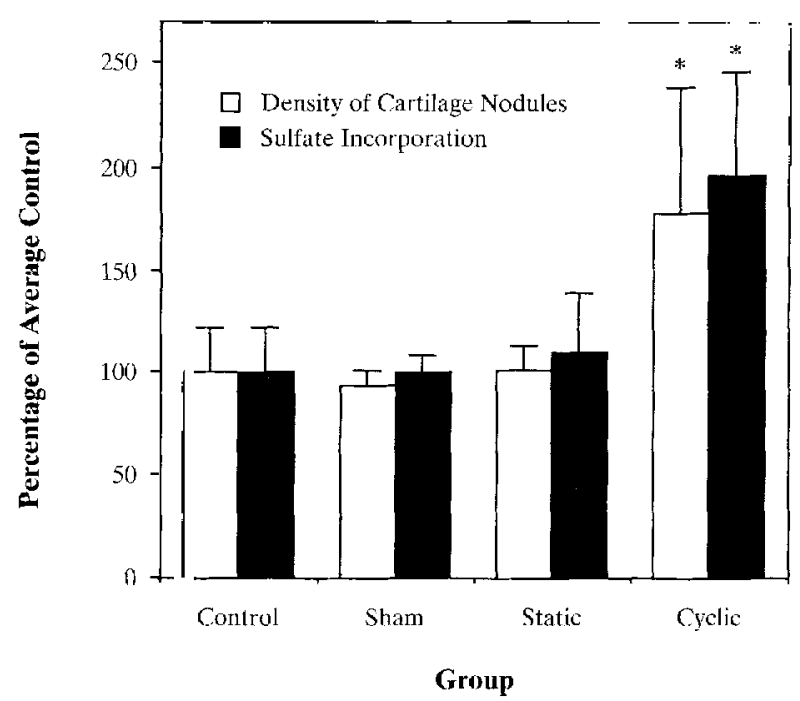

FIG. 4. Assessment of chondrogenesis at day 8 in cultures subjected to compressive loading. Values have been normalized to the average nonloaded control value $(100 \%)$. Error bars represent 1 SD. $* \mathbf{P}<0.05$.

ethanol. The disks were dehydrated in a graded series of ethanol and embedded in acrylic (JB-4; Polyscienccs, Warrington, PA, U.S.A.). Thick $(7 \mu \mathrm{m})$ vertical sections were stained with Mayer's hematoxylin and $1 \%$ toluidine blue.

Cclls were counted on a microscope with a $\times 6$ objective and $\times 10$ eycpiece containing a square grid that outlined an area of 2.78 $\mathrm{mm}^{2}$. For each disk, cells in three fields-center, mid-radius, and edge-werc counted on three separate, nonserial diamctrical sections. Two different counts were made: (a) the total number of isolated single-cellular and multicellular units, including cartilage nodules (cells within nonchondrocytic clusters and nodules were not counted individually), and (b) cartilage nodules only. Cartilage nodules were identified by cells with a relatively large cytoplasmic volume and a rounded or polygonal shape and that were surrounded by an extracellular matrix with metachromatic toluidine blue staining. Both counts werc normalized to the total crosssectional area in which they werc made. Digital inages at $\times 100$ magnification were captured with a charge-coupled device camera (TM-745; Pulnix America, Sunnyvale, CA, U.S.A.) and NIH Image software. An index of nodule size was obtained by manually outlining nodule boundaries on each microscopic field used for

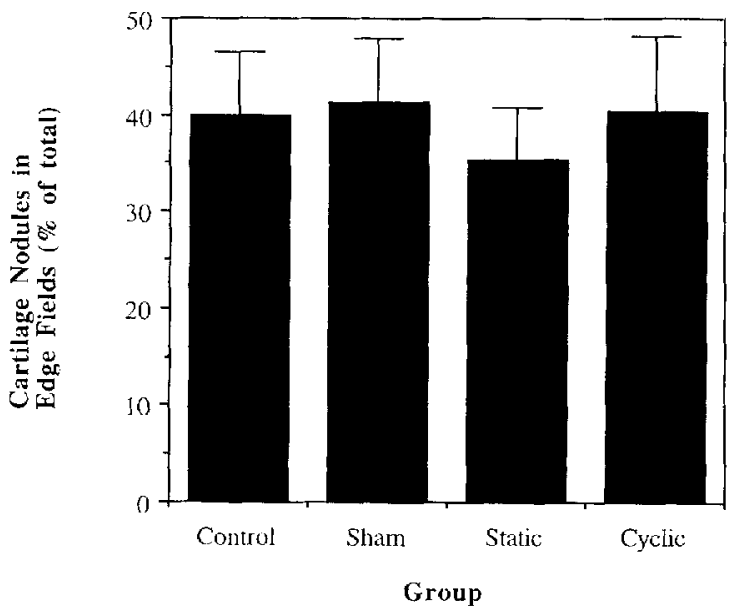

FIG. 5. Spatial distribution of cartilage nodules. The edge field included the outer $30 \%$ of the radius. Error bars represent 1 SD. counting nodules and celis. Since the nodules did not seem to be spherical or elliptical, stereomorphometric analysis was not employed to estimate their actual size. Rather, the circunscribed arcas of the nodules on three parallel planes (histologic sections) were taken as indices of three-dimensional nodule size.

\section{${ }^{35}$ S]Sulfate Incorporation}

To assess the rate of glycosaminoglycan synthesis, an indicator of chondrocyte phenotypic expression, each culture was transferred to a separate well in a 24-well dish and covered with $1 \mathrm{ml}$ of media containing $20 \mu \mathrm{Ci}\left(74 \times 10^{4} \mathrm{~Bq}\right) / \mathrm{ml}\left[{ }^{35} \mathrm{~S}\right]$ sulfate. Cells were allowed to incorporate the radiolabel for 4 hours, after which they were washed in medium containing unlabeled sulfate and digested in $1.0 \mathrm{ml}$ papain (Sigma $\mathbf{P}-3125$ [Sigma], $280 \mu \mathrm{g} / \mathrm{ml}$ in $0.05 \mathrm{M}$ sodium acetate, and $57 \mu \mathrm{M}$ cysteine- $\mathrm{HCl}, \mathrm{pH} 6.0$ ) for 12 hours at $60^{\circ} \mathrm{C}$. To separate unincorporated ${ }^{35} \mathrm{~S}, 0.5-\mathrm{ml}$ aliquots of digest were applied to PD-10 columns (Amersham Pharmacia Biotech, Piscalaway. NJ, U.S.A.), cquilibrated, and eluted with 50 $\mathrm{m} M$ sodium acetate, $\mathrm{pH}$ 6.0. The radioactivity in each of $100.5-$ $\mathrm{ml}$ fractions was quantified with a liquid scintillation counter (LS$100 \mathrm{C}$ : Beckman Instruments, Fullerton, CA, U.S.A.), and the amount of incorporated $\left[{ }^{35} \mathrm{~S}\right]$ sulfate was normalized to specimen wet wcight.

\section{Statistics}

The effect of treatment group on the proportion of cartilage nodules in the edge region was tested by one-way analysis of variance (ANOVA) $(\alpha=0.05)$. With respect to the assessments of chondrogenesis, two separate statistical analyses were performed, one with cartilage nodule density as the dependent variable and the other with radioactive sulfate incorporation. ANOVA $(\alpha=$ 0.05 ) was used to test for the effect of treatment group (nonloaded control, sham-loaded control, cyclically loaded, and statically loaded), experiment, and treatment group-experiment interaction. Pairwise comparisons between the treatment groups were made with use of Tukey's honest significant difference test.

\section{RESULTS}

Statistical analysis revealed no significant effect of experiment or treatment group-experiment interaction. However, there were significant differences between treatment groups. Therefore, all reported $\mathrm{p}$ values are those obtained from pairwise comparisons between treatment groups with Tukey's honest significant difference test.

\section{Loading}

Cyclically and statically loaded disks remained intact. On the basis of the position of the linear variable differential transformer immediately prior to loading, disks in both loading groups recovered to their full 2$\mathrm{mm}$ thickness after each of the first two loading sessions. Therefore, strains were calculated with use of an initial thickness of $2 \mathrm{~mm}$. During cyclic loading, the peak-to-peak axial disk strain was typically approximately $10 \%$ initially, tapering to approximately $5 \%$ by the end of the loading session. It rapidly dropped to approximately $6 \%$ over the initial 30 minutes of loading, declining less rapidly thereafter (Fig. 2). This dynamic strain was added to a cumulative (creep) axial gel strain that increased steadily to approximately $10 \%$. Strain histories for static loading were similar to 
the cumulative strain component of the cyclic loading (Fig. 2). These patterns of loading were consistent over all three loading sessions.

\section{Histology}

On day 8 , two cell types were present in all cultures: polygonal cells that had proliferated to form cartilage nodules, and isolated cells and multicellular units that were morphologically indistinguishable from those in day- 0 cultures (Fig. 3). In all groups, the total number of single-cellular and multicellular units, including cartilage nodules, decreased by approximately $50 \%$ from days 1 to 8 . There was very little difference in this total number between experimental groups: normalized to the average control $(100 \%)$, the totals in the sham, static, and cyclic loading groups were $103.4 \pm 14.0$, $102.2 \pm 7.3$, and $108.1 \pm 12.9 \%$, respectively. Loading be more heavily weighted by nodules in the small to mid-size range. However, the total number of nodules in the two biggest size ranges was about the same in the cyclic loading and control groups.

\section{Sulfate Incorporation}

In pilot studies of this model in our laboratory, separate analyses of gel and medium samples revealed that more than $97 \%$ of incorporated $\left[{ }^{35} \mathrm{~S}\right] \mathrm{sul}-$ fate was retained by the agarose gel, regardless of loading. Therefore, all values reported in the current study are for the gel alone and do not include any macromolecule-associated sulfate that may have escaped to the medium. The amount of sulfate incorporated by freshly isolated chick limb-bud cells was below the threshold for detection, indicating that there were few, if any, mature chondrocytes in the ini-

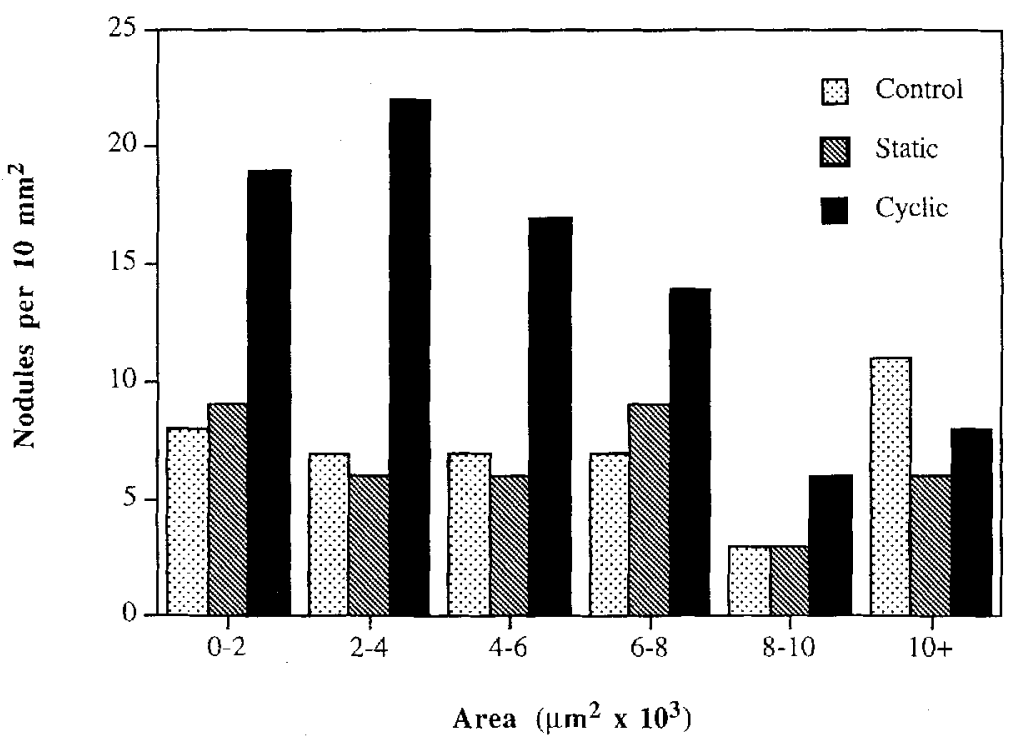

FIG. 6. Histograms of circumscribed nodule areas, measured by manually outlining nodule borders on $\times 100$ digitized images of 7 - $\mu \mathrm{m}$ sections stained with toluidine blue and hematoxylin.

did, however, influence the proportion of isolated cellular units that became chondrocytes. Cyclic loading increased cartilage nodule density on day 8 to approximately $180 \%$ that of nonloaded controls $(\mathrm{p}=0.0001)$ (Fig. 4). The effects of sham and static loading on the cartilage nodule density were negligible ( $p>0.4$ in both cases).

In all but the static loading group, more cartilage nodules-approximately $40 \%$ of the total-were found in the peripheral region (edge) of the disks than in the inner portions (mid-radius and center). Nodules were somewhat more evenly distributed in the static loading group (Fig. 5). However this difference was not statistically significant $(p=0.14)$.

Histograms of the circumscribed cartilage nodule areas are shown in Fig. 6. The histograms of the static loading and control groups were similar, but the distribution for the cyclic loading group was revealed to tial cell population. Cultures began to incorporate appreciable levels of sulfate on day 4 , and in control cultures this level had increased by roughly $250 \%$ on day 8 .

Relative to nonloaded controls, sham and static loading did not markedly change the amount of $\left[{ }^{35}\right.$ S]sulfate incorporated on day $8(p>0.6)$, but cyclic loading approximately doubled the amount of sulfate incorporation $(\mathrm{p}=0.005)$.

\section{DISCUSSION}

The objective of our research is to investigate the effects of well characterized mechanical loads on cell differentiation in vitro. In light of recent advances in cell-based therapy for repair and regeneration of articular cartilage, we chose to begin by studying the effects of uniaxial compression on chondrocyte differentiation. 
Our first aim was to establish an in vitro model that would allow application of compressive loads to cells, as well as support the chondrocyte phenotype. Agarose gel suspension culture was initially shown to be a useful system for the study of soluble factors that affect chondrogenesis (33). However, several investigators have since demonstrated that it can be adapted to apply mechanical compression to mature chondrocytes $(6,11,18)$. The experimental approach of applying controlled loads to cells suspended in agarose gel has many advantages. Agarose culture supports the chondrocyte phenotype, and the gel traps large molecules, allowing the accumulation of three-dimensional extracellular matrices (37). Also, the random dispersion of cells in a homogeneous material lends itself well to computer finite element modeling, which may be used to predict strains, stresses, and fluid flow at the microscopic level.

In contrast to previous cell-culture loading studies in the literature, we focused on testing the effects of mechanical loads on a cell population that initially included a large proportion of undifferentiated cells. It is known that chick limb-bud mesenchyme from stage 23/24 embryos possesses the potential for differentiation toward chondrogenic, myogenic, or fibroblastic phenotypes. When plated at high density, cartilage nodules appear by the fourth day in culture (1). By the eighth day, proteoglycan production peaks (21) and $50-60 \%$ of the cells display typical chondrocyte characteristics (24). In pilot studies of this model, we observed a similar temporal progression of chondrogenesis in agarose, although the percentage of cells that became chondrocytes was lower in our system. Cultures fixed immediately after cell seeding in agarose were populated by a majority of cell aggregates containing two to four cells, as well as a few larger clusters and some single cells. Small nodules of polygonal cells producing an extracellular matrix that stained metachromatically for toluidine blue were present by day 4 in culture in all groups, coinciding with an appreciable level of sulfate incorporation. Nodules continued to grow by cells dividing at the periphery, whereas cells in the interior became more widely separated by cxtracellular matrix. In cultures supplemented with ascorbic acid, the phenotype of presumptive chondrocytes was confirmed by the detection of type-II collagen expression on day 11 with monoclonal antibody staining (data not shown).

Commitment of chick limb-bud mesenchymal cells to a specific lineage and transition from one stage to the next within that lineage may depend on intrinsic and extrinsic stimuli, including soluble signals (c.g., cytokines and growth factors), mechanical signals, and environmental factors (e.g., $\mathrm{pH}$ and oxygen tension). Research into these regulatory factors has been focused on identification of soluble chemical factors that regulate differentiation and morphogenesis $(4,8,35)$. We now provide additional evidence that mechanical signals can also regulate chondrocyte differentiation to some extent. In the current study, static compressive loading at a constant stress of 4.5 $\mathrm{kPa}$ had little impact on chondrocyte differentiation whereas cyclic compressive loading at $0.33 \mathrm{~Hz}$ to a peak stress of $9.0 \mathrm{kPa}$ caused a 2 -fold increase in the level of chondrogenesis. A low-amplitude cyclic compressive strain superimposed on a small offset compressive strain was desired because of its previously demonstrated ability to stimulate chondrocyte biosynthesis over a wide range of frequencies $(6,19)$. The chosen maximum applied stress of $9.0 \mathrm{kPa}$ produced such a strain history without rupturing the agarose disks. The level of static stress was chosen such that it produced a creep strain curve similar to the nonrecoverable (cumulative) strain component of cyclically loaded disks.

The amount of sulfate incorporation and the density of cartilage nodules correlated well, suggesting that the amount of sulfate incorporated over the relatively short labeling period was essentially an estimate of the proportion of chondrocytes within the culture rather than an indicator of differences in the average level of chondrocyte biosynthetic activity. Cells were loaded during the phase of commitment to a phenotypic lineage, prior to overt differentiation, and loading was discontinued after 3 days to minimize effects on subsequent biosynthetic activity. Previous experiments in our laboratory have shown that sulfate incorporation by chick epiphyseal chondrocytes on day 8 of culture was not affected by the 3-day cyclic loading protocol (10).

Both the histological and biochemical assessments indicate that the level of chondrocyte differentiation in chick limb-bud cell-agarose cultures was nearly doubled by cyclic compressive loading at $0.33 \mathrm{~Hz}$. In particular, although the total number of isolated cellular units was approximately the same for all of the treatment groups, cartilage nodule density was significantly higher in the cyclic loading group. This result indicates that cyclic compression preferentially stimulated chondrocyte differentiation, inducing more of the starting isolated single-cellular or multicellular units to enter the chondrogenic differentiation pathway. However, cyclic loading did not seem to affect the proliferation of cells within cartilage nodules (as indicated by the lack of a rightward shift in the histogram of nodule size). On the other hand, static loading did not significantly influence chondrocyte differentiation, limit nodule size, or decrease cell viability. We did not observe static loading to induce enhancement of chondrogenesis, as did Takahashi et al. (31) using mouse limb-bud mesenchymal cells. The discrepancy could be related to any number of fac- 
tors, including differences in species (chick compared with mouse), developmental stage, duration of loading ( 2 hours per day compared with continuous), and cell-matrix interactions (agarose compared with collagen gel).

The manner in which loads were applied in our study differs from previous investigations of the effect of compressive loading on chondrocyte metabolism in agarose culture. Whereas stress was controlled in the present study, displacement or gross compressive strain was controlled in others $(6,19)$. Nonetheless, our results exhibit similar trends. Cyclic compressive loading at $1.0 \mathrm{~Hz}$ has been shown to stimulate sulfate incorporation in chondrocyte-agarose cultures $(6,19)$. In these previous studies, static loading by holding chondrocyte-agarose cylinders at a constant compressed thickness produced varying results. In one study, a $15 \%$ strain applied continuously for 48 hours inhibited glycosaminoglycan synthesis by freshly isolated chondrocytes (19). In a different study, the response to a 10-hour static compression was found to depend on the amount of accumulated extracellular matrix (6). At the earliest times in culture, static loading had little impact on biosynthesis. As the cells amassed more matrix, sensitivity to static loading increased and the cells exhibited a dose-dependent suppression in sulfate incorporation with increasing compression.

Results of the present study support the hypothesis that regulation of chondrocyte differentiation by compressive loading generally parallels its regulation of chondrocyte metabolism. Cyclic compressive loading generally stimulates matrix biosynthesis and chondrocyte differentiation, whereas the effect of static loading ranges from no effect to inhibition of glycosaminoglycan production and differentiation. Thus, the same mechanical signal or signals capable of modulating chondrocyte biosynthesis may also influence commitment to the chondrocyte phenotype or alter the rate of progression through the chondrogenic lineage, or both.

The limitations of this model include uncertainty about the exact composition of the starting cell population, which may have contained chondrocyte precursors as well as true mesenchymal stem cells not committed to any specific cell lineage $(20,27)$. Cartilage nodules may have originated from cells in various stages of differentiation. It was also not possible to determine whether a given nodule originated from a single cell or from an isolated aggregate of cells, since the agarose was seeded with individual cells and multicellular aggregates. The initial level of cell-cell interaction was the same for all treatment groups and so does not confound the results. However, determining whether cell-cell contact is a prerequisite for differentiation is important for understanding the mechanotransduction mechanism, and future studies may involve centrifugation methods to segregate the initial cell suspension according to size. There are also limitations related to the applied loads. For example, the amplitude of cyclic loading varied over a fairly wide range-5-10\% peak-to-peak gel strain-and cells could have responded to a relatively low number of high-amplitude compressive cycles instead of to a much higher number of low-amplitude loading cycles. However, in pilot studies of this model conducted in our laboratory, increasing the amplitude of cyclic loading did not enhance chondrogenesis and in some cases was detrimental. Also, chondrocytes in agarose culture have been shown to increase matrix biosynthesis in response to cyclic compressive gel strains of relatively low amplitude (6).

Several mechanisms are proposed to account for the effects of compressive loading on differentiation and biosynthesis of chondrocytes. Compressive loading of agarose gel-cell constructs raises the internal fluid (pore) pressure, causes fluid flow, and deforms the cells. During unconfined compression of agarose, the transient pressure and flow profiles are radially nonuniform. Hydrostatic pressure is highest in the center of the disk and lowest at the edge, whereas fluid flow velocity is minimal at the center and maximal around the periphery. The maximum applied stress, an estimate of fluid pressure (17), was $9.0 \mathrm{kPa}$. This pressure is on the same order as that demonstrated to increase matrix deposition by chondrocytes in suspension culture (36). Therefore, the hypothesis of Carter et al. (9) that intermittent hydrostatic pressure promotes chondrogenesis must be considered. Fluid flow has also been associated with altered chondrocyte metabolism and should be viewed as a possible mechanism of influence in the current study. Compression-induced fluid flow may have enhanced delivery of certain large, soluble differentiation factors whose diffusion was hindered in nonloaded cultures, as experiments conducted in our laboratory indicate that the equilibration time for radioactive amino acids in agarose is on the order of several hours (unpublished data). In addition, streaming potentials, such as have been measured in cell-laden agarose cultures (6), may have been created by the compression-induced flow of ions in the fluid phase past immobilized fixed charges on the agarose and glycosaminoglycan chains. There was a higher concentration of cartilage nodules within the outer ring of disks in all groups, but cyclic loading did not alter the radial distribution of nodules (i.e., did not preferentially stimulate differentiation in either the central core or outer ring). It is believed that the higher concentration of cartilage nodules near the outer edge of disks resulted from the shorter diffusion distance for cells near the edge but that the effects of load- 
induced fluid flow over the short-term loading periods were overshadowed by the diffusional characteristics of the nonloaded state for all treatment groups. Furthermore, since loading was applied during the initial 3 days in culture before substantial glycosaminoglycan had been synthesized, streaming potentials would have been minimal and not likely responsible for the observed stimulation of cell differentiation. Therefore, our results do not support either the hydrostatic pressure or fluid flow theory regarding the chondrogenic component of unconfined loading.

It is also possible that chondrocyte differentiation was precipitated by direct cell or nuclear deformation. Chondrocytes suspended in agarose gel undergo shape and volumetric changes under externally applied strains $(11,18)$. Cell deformation may have activated mechanically gated ion channels in the cell membrane, initiating an intracellular signaling cascade. Furthermore, cell deformation is associated with alterations to the cell cytoskeleton; several studies indicate that integrity of the actin (microfilaments) and tubulin (microtubules) cytoskeletal elements is the source of differentiation-regulatory signals. For example, cytochalasin $\mathrm{B}$, a drug that destabilizes actin microfilaments, enhanced chondrocyte differentiation $(3,5)$, whereas exposure to colchicine, a drug that disrupts microtubules, suppressed it (32). Also, Buschmann et al. (7) demonstrated that local changes in glycosaminoglycan synthesis correlated with structural changes to the cell and nucleus, and they proposed that alterations in the shape and volume of the cell could modify gene expression by way of mRNAcytoskeletal interactions or direct nuclear deformation. Chondrocyte biosynthesis was recently reported to be stimulated by cyclic shear loading in a flowindependent manner, demonstrating the potential for cells to respond to a purely deviatoric stress (16). Given the increase in chondrocyte differentiation throughout the agarose disks, our results seem to support the theory that dynamic deviatoric stress is the primary chondrogenic component of the cyclic unconfined compression. Thus, cell deformation may bc of primary importance. The reason that cells responded to dynamic but not to static compression is unknown and begs further investigation.

In summary, a $0.33-\mathrm{Hz}$ cyclic compressive load applied for only 2 hours per day significantly enhanced chondrocyte differentiation in agarose gel cultures of chick limb-bud cells, whereas static compression had a negligible effect. Our data support the hypothesis that the mechanical environment contributes to the regulation of chondrocyte differentiation and that its influence may be similar to that which it exerts on the metabolic rate of mature chondrocytes. Ongoing studies include finite element analysis to correlate aspects of the cell's mechanical environment with the biological response to loading, experiments to help identify the major chondrogenic component of cyclic compression (e.g., hydrostatic pressure, fluid flow, and cell deformation), and a search for changes in gene expression induced by mechanical loading.

Acknowledgment: The authors would like to thank Dennis Kayner, Mark Stock, and John Baker for their technical assistance and Dr. David Mooney for his advice in preparing this manuscript. This study was supported by National Institutes of Health Grant AR20557, the Whitaker Foundation, the Frederick J. Fischer Endowment Fund, and the Horace H. Rackham School of Graduate Studies.

\section{REFERENCES}

1. Ahrens PB, Solursh M, Rciter RS: Stage-related capacily for limb chondrogenesis in cell culture. Dev Biol 60:69-82, 1977

2. Ashhurst DE: The influence of mechanical conditions on the healing of experimental fractures in the rabbit: a microscopical study. Philos Trans $R$ Soc Lond [Biol] 313:271-302, 1986

3. Benya PD, Padilla SR: Dihydrocytochalasin $B$ enhances transforming growth factor-beta-induced reexpression of the differentiated chondrocyte phenotype without stimulation of collagen synthesis. Exp Cell Res 204:268-277, 1993

4. Biddulph DM, Sawyer LM, Dozier MM: Chondrogenesis in chick limb mesenchyme in vitro derived from distal limb bud tips: changes in cyclic AMP and in prostaglandin responsiveness. I Cell Physiol 136:81-87, 1988

5. Brown PD, Benya PD: Alterations in chondrocyte cytoskeletal architecture during phenotypic modulation by retinoic acid and dihydrocytochalasin $\mathrm{B}$-induced reexpression. $J$ Cell Biol 106:171-179, 1988

6. Buschmann MD, Gluzband YA, Grodzinsky AJ, Hunziker EB: Mechanical compression modulates matrix biosynthesis in chondrocyte/agarose culture. I Cell Sci 108:1497-1508, 1995

7. Buschmann MD, Hunziker EB, Kim YJ, Grodzinsky AJ: Altered aggrecan synthesis correlates with cell and nucleus structurc in statically compressed cartilage. J Cell Sci 109:499 508,1996

8. Carrington JL, Chen P, Yanagishita M, Reddi AH: Osteogenin (bone morphogenctic protein-3) stimulates cartilage formation by chick limb bud cells in vitro. Dev Biol 146:406-415, 1991

9. Carter DR, Or TE, Fyhrie DP, Schurman DJ: Influences of mechanical stress on prenatal and postnatal skeletal development. Clin Orthop 219:237-250, 1987

10. Elder $\mathrm{SH}$ : Eflects of compressive loading on chondrocyle differentiation in a novel chick limb bud cell-agarose model of chondrogenesis [Ph.D. thesis]. Ann Arbor, UMI Dissertation Services, 1998

11. Freeman PM, Nataraja RN, Kimura JH, Andriacchi TP: Chondrocyte cells respond mochanically to compressive loads. $I$ Orthop Res 12:311-320, 1994

12. Hall BK: In vitro studies on the mechanical evocation of advenitious cartilage in the chick. $J$ Exp Zool 168:283-305, 1968

13. Hamburger V, Hamilton H: A series of normal stages in development of the chick embryo. J Morphol 88:49-92, 1951

14. Hattori $\mathrm{T}$, Ide $\mathrm{H}$ : Limb bud chondrogenesis in cell culture, with particular reference to serum concentration in the culture medium. Exp Cell Res 150:338-346, 1984

15. Hunziker EB, Herrmann W, Schenk RK: Improved cartilage lixation by ruthenium hexammine trichloride (RHT): a prerequisite for morphometry in growth cartilage. $J$ Vltrastruc Res 81:1-12, 1982

16. Jin M, Levenston M, Frank F, Grodzinsky A: Regulation of cartilage matrix metabolism by dynamic lissue sheat strain. Tran.; Orthop Res Soc 24:169, 1999

17. Kim Y-J, Bonassar LJ, Grodzinsky AJ: The role of cartilage streaming potential, fluid flow and pressure in the stimulation of chondrocyte biosynthesis during dynamic compression. J Biomech 28:1055-1066, 1995 
18. Lee DA, Bader DL: The development and characterization of an in vitro system to study strain-induced cell deformation in isolated chondrocytes. In Vitro Cell Dev Biol 31:828-835, 1995

19. Lee DA, Bader DL: Compressive strains at physiological frequencies influence the metabolism of chondrocytes seeded in agarose. J Orthop Res 15:181-188, 1997

20. Lennon DP, Osdoby P, Carrino DA, Vertel BM, Caplan AI: Isolation and characterization of chondrocytes and nonchondrocytes from high-density chick limb bud cell cultures. $J$ Craniofac Genet Dev Biol 3:235-251, 1983

21. Lohmander LS, Hascall VC, Caplan AI: Effects of 4-methyl umbelliferyl- $\beta$-D-xylopyranoside on chondrogenesis and proteoglycan synthesis in chick limb bud mesenchymal cell cultures. I Biol Chem 254:10551-10561, 1979

22. Murray PDF, Drachman BD: The role of movement in the development of joints and related structures: the head and neck in the chick embryo. J Embryo Exp Morphol 22:349-371, 1969

23. O'Driscoll SW, Kecley FW, Salter RB: The chondrogenic potential of free autogenous periosteal grafts for biological resurfacing of major full-thickness defects in joint surfaces under the influence of continuous passive motion: an experimental investigation in the rabbit. $J$ Bone Joint Surg [Am] 68:1017-1035, 1986

24. Osdoby P, Caplan AI: Osteogenesis in cultures of limb mesenchymal cells. Dev Biol 73:84-102, 1979

25. Palmoski MJ, Brandt KD: Effects of static and cyclic compressive loading on articular cartilage plugs in vitro. Arthritis Rheum 27:675-681, 1984

26. Parkkinen JJ, Lammi MJ, Helminen HJ, Tammi M: Local stimulation of proteoglycan synthesis in articular cartilage explants by dynamic compression in vitro. J Orthop Res 10:610620,1992

27. Paulsen DF, Che WD, Pang L, Johnson B, Okello D: Stageand region-dependent chondrogenesis and growth of chick wing-bud mesenchyme in serum-containing and defined tissue culture media. Dev Dyn 200:29-52, 1994

28. Pauwels F: A new theory concerning the influence of mechanical stimuli on the differentiation of the supporting tissues. In:
Biomechanics of the Locomotor Apparatus: Contributions on the Functional Anatomy of the Locomotor Apparatus, pp 375 407. Berlin, Springer-Verlag, 1980

29. Sah RL-Y, Kim Y-J, Doong J-YH, Grodzinsky AJ, Plaas AHK, Sandy JD: Biosynthetic response of cartilage explants to dynamic compression. J Orthop Res 7:619-636, 1989

30. Takahashi I, Mizoguchi I, Nakamura M, Sasano Y, Saitoh S, Kagayama M, Mitani H: Effects of expansive force on the differentiation of midpalatal suture cartilage in rats. Bone $18: 341-348,1996$

31. Takahashi I, Nuckolls GH, Takahasi K, Tanaka O, Semba I, Dashner R, Shum L, Slavkin HC: Compressive force promotes sox9, type II collagen and aggrecan and inhibits IL-1 $\beta$ expression resulting in chondrogenesis in mouse embryonic limb bud mesenchymal cells. J Cell Sci 111:2067-2076, 1998

32. Takigawa M, Takano T, Shirai E, Suzuki F: Cytoskeleton and differentiation: effects of cytochalasin B and colchicine on cxpression of the differentiated phenotype of rabbit costal chondrocytes in culture. Cell Differ 14:197-204, 1984

33. Thompson AY, Piez KA, Scyedin SM: Chondrogenesis in agarose gel culture: a model for chondrogenic induction, proliferation and differentiation. Exp Cell Res 157:483-494, 1985

34. Torzilli PA, Grigiene R, Huang C, Friedman SM, Doty SB, Boskey AL, Lust G: Characterization of cartilage metabolic response to static and dynamic stress using a mechanical explant test system. J Biomech 30:1-9, 1997

35. Tsonis PA: 1,25-Dihydroxyvitamin D3 stimulates chondrogenesis of the chick limb bud mesenchymal cells [published erratum appears in Dev Biol 146:264, 1991]. Dev Biol 143:130134,1991

36. Veldhuijzen JP, Huisman AH, Vermeiden JPW, PrahlAndersen B: The growth of cartilage cells in vitro and the cffect of intermittent compressive force: a histological evaluation. Connect Tissue Res 16:187-196, 1987

37. Verbruggen G, Veys EM, Wieme N, Malfait AM, Gijselbrecht L, Nimmegeers J, Almquist KF, Broddelez C: The synthesis and immobilisation of cartilage-specific proteoglycan by human chondrocytes in different concentrations of agarose. Clin Exp Rheumatol 8:371-378, 1990 